\title{
Article \\ Clinical Characteristics and Outcomes of Fungal Keratitis in the United Kingdom 2011-2020: A 10-Year Study
}

\author{
Darren Shu Jeng Ting ${ }^{1,2, *\left(\mathbb{C}, \text { Mohamed Galal }^{3} \text {, Bina Kulkarni }{ }^{2}(\mathbb{D} \text {, Mohamed S. Elalfy }\right.}{ }^{3,4}$, Damian Lake ${ }^{3}$, \\ Samer Hamada ${ }^{3}$, Dalia G. Said ${ }^{1,2,4}$ and Harminder S. Dua ${ }^{1,2}$ \\ 1 Academic Ophthalmology, Division of Clinical Neuroscience, School of Medicine, University of Nottingham, \\ Nottingham NG7 2RD, UK; daliagsaid@gmail.com (D.G.S.); profdua@gmail.com (H.S.D.) \\ 2 Queen's Medical Centre, Nottingham NG7 2RD, UK; bina.kulkarni@nuh.nhs.uk \\ 3 Queen Victoria Hospital, East Grinstead RH19 3DZ, UK; mohamed.galal@nhs.net (M.G.); \\ m.elalfy@nhs.net (M.S.E.); damian.lake@nhs.net (D.L.); s.hamada@nhs.net (S.H.) \\ 4 Research Institute of Ophthalmology, Giza 12557, Egypt \\ * Correspondence: ting.darren@gmail.com
}

Citation: Ting, D.S.J.; Galal, M.; Kulkarni, B.; Elalfy, M.S.; Lake, D.; Hamada, S.; Said, D.G.; Dua, H.S. Clinical Characteristics and Outcomes of Fungal Keratitis in the United Kingdom 2011-2020: A 10-Year Study. J. Fungi 2021, 7, 966. https://doi.org/10.3390/jof7110966

Academic Editor: Joseph M. Bliss

Received: 4 October 2021

Accepted: 8 November 2021

Published: 12 November 2021

Publisher's Note: MDPI stays neutral with regard to jurisdictional claims in published maps and institutional affiliations.

Copyright: (c) 2021 by the authors. Licensee MDPI, Basel, Switzerland. This article is an open access article distributed under the terms and conditions of the Creative Commons Attribution (CC BY) license (https:// creativecommons.org/licenses/by/ $4.0 /)$.

\begin{abstract}
Fungal keratitis (FK) is a serious ocular infection that often poses significant diagnostic and therapeutic dilemmas. This study aimed to examine the causes, clinical characteristics, outcomes, and prognostic factors of FK in the UK. All culture-positive and culture-negative presumed FK (with complete data) that presented to Queen's Medical Centre, Nottingham, and the Queen Victoria Hospital, East Grinstead, between 2011 and 2020 were included. We included 117 patients ( $n=117$ eyes) with FK in this study. The mean age was $59.0 \pm 19.6$ years (range, $4-92$ years) and $51.3 \%$ of patients were female. Fifty-three fungal isolates were identified from $52(44.4 \%)$ culturepositive cases, with Candida spp. (33, 62.3\%), Fusarium spp. (9, 17.0\%), and Aspergillus spp. (5, 9.4\%) being the most common organisms. Ocular surface disease $(60,51.3 \%)$, prior corneal surgery $(44$, $37.6 \%$ ), and systemic immunosuppression $(42,35.9 \%)$ were the three most common risk factors. Hospitalisation for intensive treatment was required for $95(81.2 \%)$ patients, with a duration of 18.9 \pm 16.3 days. Sixty-six (56.4\%) patients required additional surgical interventions for eradicating the infection. Emergency therapeutic/tectonic keratoplasty was performed in 29 (24.8\%) cases, though $13(44.8 \%)$ of them failed at final follow-up. The final corrected-distance-visual-acuity (CDVA) was $1.67 \pm 1.08 \log$ MAR. Multivariable logistic regression analyses demonstrated increased age, large infiltrate size $(>3 \mathrm{~mm})$, and poor presenting CDVA $(<1.0 \operatorname{logMAR})$ as significant negative predictive factors for poor visual outcome (CDVA of $<1.0 \log$ MAR) and poor corneal healing ( $>60$ days of healing time or occurrence of corneal perforation requiring emergency keratoplasty; all $p<0.05$ ). In conclusion, FK represents a difficult-to-treat ocular infection that often results in poor visual outcomes, with a high need for surgical interventions. Innovative treatment strategies are urgently required to tackle this unmet need.
\end{abstract}

Keywords: Candida; corneal infection; corneal ulcer; contact lens; fungal infection; Fusarium; infectious keratitis; keratoplasty

\section{Introduction}

Infectious keratitis (IK) represents the leading cause of corneal blindness globally, with an estimated incidence of 2.5-799 cases per 100,000 population/year [1-3]. Subject to geographical, temporal and seasonal variations, bacteria and fungi are the most common causative organisms for IK, while viral and parasitic infections are less commonly reported [3-9]. The variations in the incidence and causes are mainly attributed to an underlying discrepancy in the risk factors (particularly contact lens wear, trauma and ocular surface disease), climate, access to a healthcare system, personal and environmental hygiene, and level of education [1]. 
Fungal keratitis (FK) often poses significant diagnostic and therapeutic dilemmas. It is most commonly observed in tropical/subtropical countries and regions with prevalent agricultural activity, accounting for $23-63 \%$ of all IK cases in these regions $[1,10,11]$. Compared to bacterial keratitis, FK is more frequently associated with guarded visual prognosis, primarily caused by the significant diagnostic challenge (due to low and slow culture yield), the propensity to deeper infection affecting the posterior cornea, limited antifungal treatment option, and resistance to treatment $[4,12]$. In addition, many cases of FK usually require therapeutic keratoplasty to achieve complete resolution of the disease, with many of them affected by the recurrence of infection or uncontrolled infection progressing to endophthalmitis and eventuating in evisceration/enucleation [12-16].

To date, the majority of the FK studies reported in the literature were conducted in developing or tropical/subtropical regions, including India, China and Nepal, where FK is more prevalent $[4,17-23]$. However, the results of those studies may not be readily applicable to populations in developed or temperate regions as the population characteristics, risk factors, underlying causes and management of FK can vary significantly [1]. So far, there was only one large study that had specifically examined the outcome of FK in the United Kingdom (UK) in the past decade [24]. In view of the paucity of the literature and the clinical significance of the disease, this study aimed to examine the clinical characteristics, risk factors, outcomes, and prognostic factors of FK in the UK.

\section{Materials and Methods}

This was a retrospective study of all cases of FK that presented to two of the tertiary ophthalmic referral centres in the UK, namely the Queen's Medical Centre, Nottingham, and the Queen Victoria Hospital, East Grinstead, between January 2011 and December 2020 (a 10-year period). The study was approved as a clinical audit by the Clinical Governance team in both Nottingham University Hospitals NHS Trust (Ref: 19-265C) and Queen Victoria Hospital NHS Foundation Trust (Ref: 21-539).

\subsection{Case Identification and Definition}

Potential cases of FK were first identified via the local microbiological database and hospital pharmacy database (based on the use of a topical antifungal treatment). Subsequently, the medical case records were examined to confirm the eligibility of the potential cases prior to inclusion into the study. In anticipation of the low prevalence of FK in the UK, both culture-positive and culture-negative presumed FK cases were included in this study. Culture-positive FK was defined as the presence of clinical FK with confirmation of the causative fungal pathogen on microbiological culture. Culture-negative presumed FK was diagnosed based on the presence of typical clinical findings (see below) and/or suggestive clinical course such as non-improvement/deterioration with intensive topical antibiotic treatment alone, which subsequently required intensive topical antifungal treatment to improve and resolve the infection. Co-infection of FK with culture-positive bacterial keratitis cases were included but pure bacterial keratitis cases were excluded from this study. Identification of fungal and bacterial infection was primarily based on conventional culture morphologies. Other types of infection, including viral and parasitic keratitis, were also excluded from this study.

\subsection{Data Collection}

Relevant data, including demographic factors, risk factors, clinical characteristics, types of fungi, corrected-distance-visual-acuity (CDVA), pre-existing ocular co-morbidities that could affect the visual prognosis, management, outcome and complications, were collected using a standardised Microsoft Excel proforma. Risk factors were divided into (1) contact lens wear; (2) trauma; (3) ocular surface diseases (e.g., dry eye, meibomian gland dysfunction, neurotrophic keratopathy, previous corneal infection, recurrent corneal erosion syndrome, limbal stem cell deficiency, cicatricial conjunctivitis, band keratopathy, and bullous keratopathy); (4) lid diseases (e.g., entropion, ectropion, distichiasis/trichiasis, 
and exposure keratopathy); (5) use of topical corticosteroids; (6) previous/recent history of corneal surgery (e.g., corneal graft, pterygium surgery, corneal collagen cross-linking and corneal debridement/delamination), and (7) systemic immunosuppression (e.g., diabetes, systemic immunosuppressive treatment, malnutrition, and immunodeficiency). Slit-lamp photographs and anterior segment optical coherence tomography (AS-OCT) were examined for the presence of any typical characteristics of FK, including the feathery border of the infiltrate, ring infiltrate, satellite lesions (small infiltrates near the main infiltrative lesion), multifocal lesions ( $\geq 2$ infiltrates either close or far apart from each other), and deep stromal/endothelial plaque (Figure 1A-C). Deep stromal infection was defined as the involvement of the posterior $1 / 3$ of the cornea [15].
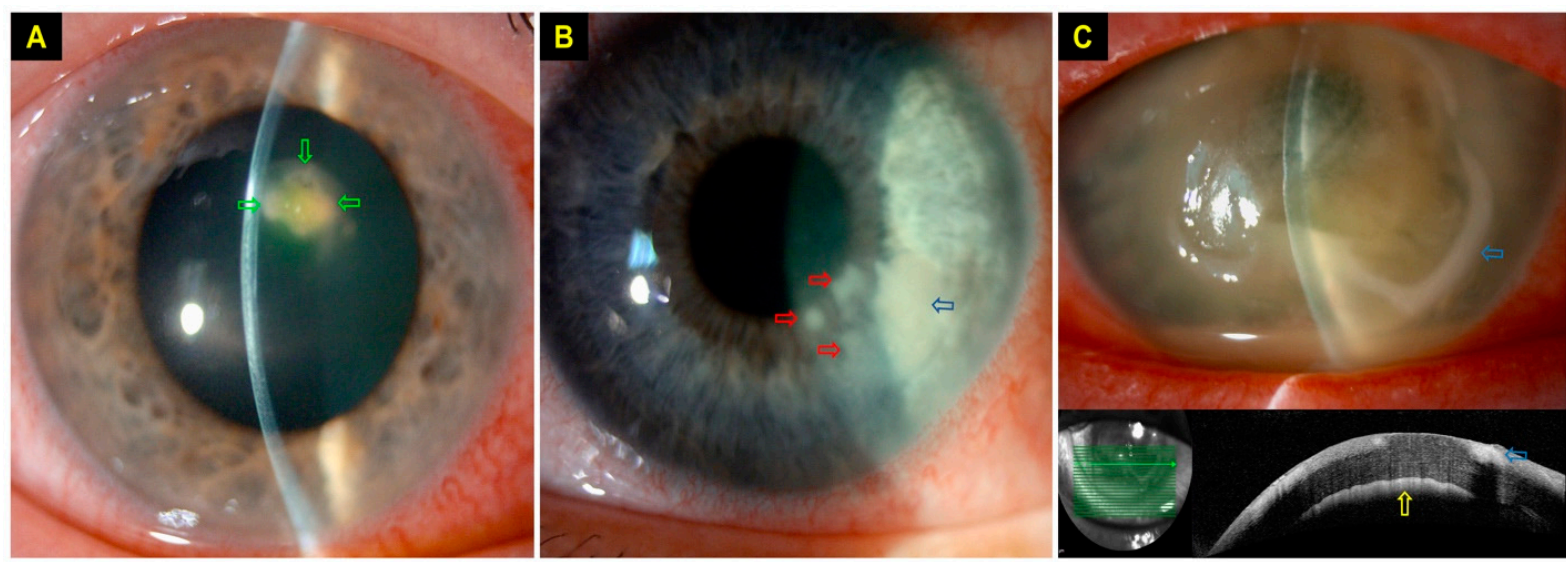

Figure 1. Slit-lamp photography demonstrating typical signs of fungal keratitis (FK). (A) A small contact lens (CL)-related FK with multifocal infiltrates (green arrows) with feathery borders. (B) A CL-related FK with multifocal infiltrates of feathery borders, with an area of main infiltrate (blue arrow) and three satellites lesions (red arrows). (C) A case of severe FK with hypopyon, ring infiltrate (blue arrows) and endothelial plaque (yellow arrow).

A number of clinical parameters used in this study were defined based on our previous study [25]. The size of the epithelial defect and infiltrate was categorised as very small $(<1 \mathrm{~mm})$, small (1-3 mm), moderate $(3.1-6 \mathrm{~mm})$ or large $(>6 \mathrm{~mm})$, based on the maximum linear dimension. The location of the ulcer was divided into central (any part of the ulcer affecting the visual axis), paracentral (in between the central and peripheral location), and peripheral (the entire ulcer was within $3 \mathrm{~mm}$ from the limbus). Recurrence was defined as the re-occurrence of FK after complete resolution of the previous FK episode, irrespective of the time interval between the first and subsequent infective episode. To avoid any duplication of the patient's risk factors in bilateral or recurrent FK cases, we only included one eye per patient in this study. For recurrent cases, only the first FK episode was included and analysed, regardless of the laterality of infection in the subsequent infective episode.

\section{Microbiological Culture, Diagnosis and Treatment}

Based on the departmental guideline for IK, all patients presented with corneal ulcer(s) of $>1 \mathrm{~mm}$ diameter, central location or sight-threatening, associated with significant anterior chamber reaction, or atypical presentation were subjected to the microbiological investigation such as corneal scraping for microscopy (with Gram staining), microbiological culture and sensitivity testing [3,5]. Corneal scrapes were inoculated on chocolate agar (for fastidious organisms), blood agar (for bacteria) and Sabouraud dextrose agar (for fungi). For suspected cases of Acanthamoeba keratitis, corneal swab and/or epithelial biopsy was obtained for polymerase chain reaction (PCR) testing [5]. All cultures were incubated for at least 1 week (and up to 3 weeks for suspected Acanthamoeba keratitis). In vivo confocal microscopy (IVCM) using the Heidelberg Retinal Tomography (HRT) II/III with Rostock Cornea Module (Heidelberg Engineering Ltd., Hertfordshire, UK) was utilised to aid the diagnosis or exclusion of fungal and Acanthamoeba keratitis [5]. 
During the initial treatment phase, all patients with FK were treated with intensive hourly antifungal topical treatment, using either voriconazole $1 \%$, natamycin 5\%, amphotericin B $0.15 \%$ or a combination of them, based on the severity of infection, types of fungi and clinicians' preference. Further modification to the treatment regimen and addition of oral antifungal treatment were made according to the patient's clinical progress and culture results.

\section{Statistical Analysis}

Statistical analysis was performed using SPSS version 27.0 (IBM SPSS Statistics for Windows, Armonk, NY, USA). For descriptive and analytic purposes, the cases were divided into culture-positive and culture-negative FK cases. Comparison between groups was conducted using Pearson's Chi-square or Fisher's Exact test where appropriate for categorical variables, and T-test or Mann-Whitney U test for continuous variables. Normality of data distribution was assumed if the skewness and kurtosis $\mathrm{z}$-values were between -1.96 and +1.96 and the Shapiro-Wilk test $p$-value was $>0.05$. All continuous data were presented as mean \pm standard deviation (SD) and/or 95\% confidence interval (CI).

The main outcome measures were corrected-distance-visual-acuity (CDVA) and time to complete corneal healing, defined as complete resolution of infection with corneal reepithelialisation. Snellen vision was converted to logMAR vision for analytic purposes. Counting fingers (CF), hand movement (HM), perception to light (PL) and no perception to light (NPL) were quantified as $1.9 \log \mathrm{MAR}, 2.3 \log \mathrm{MAR}, 2.8 \log \mathrm{MAR}$ and $3.0 \log \mathrm{MAR}$ respectively $[25,26]$. For patients who underwent keratoplasty (either therapeutic, tectonic or optical), the CDVA immediately prior to keratoplasty was used as the final visual outcome. A final CDVA of 3.0 logMAR was assigned to cases that eventuated with evisceration or enucleation. Logistic regression analysis was performed to examine for any potential prognostic factors for poor visual outcome, defined as corrected-distance-visual-acuity (CDVA) of $<1.0 \operatorname{logMAR}$ (or $<6 / 60$ ) and poor corneal healing, defined as $>60$ days to achieve complete corneal healing from the initial presentation or required tectonic/therapeutic keratoplasty, evisceration or enucleation to resolve the infection. $p$-value of $<0.05$ was considered statistically significant.

\section{Results}

\subsection{Overall Description}

During the 10-year study period, 117 patients ( $n=117$ eyes) with FK were included. The mean age was $59.0 \pm 19.6$ years (range, $4-92$ years), 51.3\% of patients were female and $57.3 \%$ of cases affected the right eye (Table 1 ). The mean follow-up duration was $26.2 \pm 26.5$ months. A total of $52(44.4 \%)$ culture-positive FK cases and $65(55.6 \%)$ culturenegative presumed FK cases were included (Table 1). Thirty-two (27.3\%) cases were treated as mixed bacterial/fungal keratitis.

\subsection{Causative Organisms and Risk Factors}

Candida spp. $(33,62.3 \%)$ was shown to be the most common fungal pathogen, followed by Fusarium spp. (9, 17.0\%) and Aspergillus spp. (5, 9.4\%; Table 2). Almost all (51, 98.1\%) cases were caused by a single fungal pathogen, except for one (1.9\%) case which was caused by poly-fungal infection secondary to Rhodotorula spp. and Alternaria spp. Of all cases, $32(27.3 \%)$ cases were affected by bacterial co-infection, with Staphylococci spp. $(16,13.7 \%)$ as the most common cause. No significant difference in age $(p=0.14)$, gender $(p=0.34)$ and hospital location ( $p=0.57$ ) was found between yeast and filamentous FK (Table 3). 
Table 1. Summary of the demographic factors, risk factors and baseline clinical characteristics of fungal keratitis presented to Queen's Medical Centre (QMC), Nottingham, UK and Queen Victoria Hospital QVH), East Grinstead, UK.

\begin{tabular}{|c|c|c|c|c|}
\hline \multirow{2}{*}{ Parameters } & All Cases & Culture-Proven & Culture-Negative & \multirow{2}{*}{$p$-Value $\#$} \\
\hline & Total N = 117; N (\%) & Total $\mathrm{N}=52 ; \mathrm{N}(\%)$ & Total $\mathrm{N}=65 ; \mathrm{N}(\%)$ & \\
\hline Hospital & & & & 0.12 \\
\hline QVH & $87(74.4)$ & $35(67.3)$ & $52(80.0)$ & \\
\hline QMC & $30(25.6)$ & $17(32.7)$ & $13(20.0)$ & \\
\hline Age, years & $59.0 \pm 19.6$ & $56.5 \pm 20.8$ & $61.1 \pm 18.5$ & 0.21 \\
\hline Gender & & & & 0.11 \\
\hline Female & $60(51.3)$ & $31(59.6)$ & $29(44.6)$ & \\
\hline Male & $57(48.7)$ & $21(40.4)$ & $36(55.4)$ & \\
\hline Laterality & & & & 0.23 \\
\hline Left & $50(42.7)$ & $19(36.5)$ & $31(47.7)$ & \\
\hline Right & $67(57.3)$ & $33(63.5)$ & $34(52.3)$ & \\
\hline Risk factors $\$$ & & & & 0.37 \\
\hline $\mathrm{OSD}^{*}$ & $60(51.3)$ & $30(57.7)$ & $30(46.2)$ & \\
\hline Prior corneal surgery & $44(37.6)$ & $18(34.6)$ & $26(40.0)$ & \\
\hline Immunosuppression ** & $42(35.9)$ & $21(40.4)$ & $21(32.3)$ & \\
\hline Contact lens wears & $28(23.9)$ & $17(32.7)$ & $11(16.9)$ & \\
\hline Topical corticosteroids & $19(16.2)$ & $10(19.2)$ & $9(13.8)$ & \\
\hline Lid diseases $* * *$ & $16(13.7)$ & $4(7.7)$ & $12(18.5)$ & \\
\hline Trauma & $7(6.0)$ & $3(5.8)$ & $4(6.2)$ & \\
\hline Presenting CDVA, in logMAR & & & & $\underline{0.038}$ \\
\hline $0.0-0.3$ & $16(13.7)$ & $10(19.3)$ & $6(9.2)$ & \\
\hline$<0.3-0.6$ & $7(6.0)$ & $4(7.7)$ & $3(4.6)$ & \\
\hline$<0.6-1.0$ & $11(9.4)$ & $8(15.4)$ & $3(4.6)$ & \\
\hline$<1.0$ & $83(70.9)$ & $30(57.7)$ & $53(81.5)$ & \\
\hline Size of epithelial defect & & & & 0.22 \\
\hline Very small (<1 mm) & $6(5.1)$ & $2(3.8)$ & $4(6.2)$ & \\
\hline Small $(1-3 \mathrm{~mm})$ & $38(32.5)$ & $19(36.5)$ & $19(29.2)$ & \\
\hline Moderate (3.1-6 mm) & $45(38.5)$ & $23(44.2)$ & $22(33.8)$ & \\
\hline Large $(>6 \mathrm{~mm})$ & $28(23.9)$ & $8(15.4)$ & $20(30.8)$ & \\
\hline Size of infiltrate & & & & 0.52 \\
\hline Very small (<1 mm) & $10(8.5)$ & $5(9.6)$ & $5(7.7)$ & \\
\hline Small $(1-3 \mathrm{~mm})$ & $45(38.5)$ & $21(40.4)$ & $24(36.9)$ & \\
\hline Moderate $(3.1-6 \mathrm{~mm})$ & $47(40.2)$ & $22(42.3)$ & $25(38.5)$ & \\
\hline Large $(>6 \mathrm{~mm})$ & $15(12.8)$ & $4(7.7)$ & $11(16.9)$ & \\
\hline Location & & & & 0.71 \\
\hline Central & $70(59.8)$ & $29(55.8)$ & $41(63.1)$ & \\
\hline Paracentral & $34(29.0)$ & $17(32.7)$ & $17(26.2)$ & \\
\hline Peripheral & $13(11.1)$ & $6(11.5)$ & $7(10.8)$ & \\
\hline Hypopyon & & & & 0.76 \\
\hline Yes & $40(34.2)$ & $17(32.7)$ & $23(35.4)$ & \\
\hline No & $77(65.8)$ & $35(67.3)$ & $42(64.6)$ & \\
\hline Hospitalisation required & & & & 0.29 \\
\hline Yes & $95(81.2)$ & $40(76.9)$ & $55(84.6)$ & \\
\hline No & $22(18.8)$ & $12(33.1)$ & $10(15.4)$ & \\
\hline Duration of hospitalisation, days & $18.9 \pm 16.3$ & $17.5 \pm 15.0$ & $19.8 \pm 17.2$ & 0.5 \\
\hline Co-infection with bacteria & & & & 0.18 \\
\hline Yes & $32(27.3)$ & $11(21.2)$ & $21(32.3)$ & \\
\hline No & $85(72.7)$ & $41(78.8)$ & $44(67.7)$ & \\
\hline Need for surgical intervention (s) & & & & 0.62 \\
\hline Yes & $66(56.4)$ & $28(53.8)$ & $38(58.5)$ & \\
\hline No & $51(43.6)$ & $24(46.2)$ & $27(41.5)$ & \\
\hline
\end{tabular}

OSD = Ocular surface disease; $\mathrm{CDVA}=$ Corrected-distance-visual-acuity. Continuous values are presented as mean \pm standard deviation (SD). \$ Some patients had more than 1 risk factor identified. * Included dry eye disease, meibomian gland disease, neurotrophic keratopathy, previous corneal infection, corneal erosion syndrome, limbal stem cell deficiency, cicatricial conjunctivitis, band keratopathy and bullous keratopathy. ${ }^{* *}$ Included diabetes, use of systemic immunosuppressive drugs, malnutrition and immunodeficiency. ${ }^{* * *}$ Included lid ectropion, entropion, distichiasis/trichiasis and exposure keratopathy. ${ }^{\#}$ Comparison between culture-positive and culture-negative cases. Chi-square and unpaired $T$-test were used for categorical and continuous variables, respectively. The significant value is underlined. 
Table 2. Causative organisms of fungal keratitis and/or co-infection with bacteria that presented to the Queen's Medical Centre, Nottingham, UK and Queen Victoria Hospital, East Grinstead, UK, between 2011 and 2020.

\begin{tabular}{lc}
\hline \multicolumn{1}{c}{ Organisms } & $\mathbf{N} \mathbf{( \% )}$ \\
\hline Fungi & \\
Total & $53(100)$ \\
Yeast & $33(62.3)$ \\
Candida spp. & $33(62.3)$ \\
Filamentous fungi & $19(35.8)$ \\
Fusarium spp. & $9(17.0)$ \\
Aspergillus spp. & $5(9.4)$ \\
Peniophora spp. & $2(3.8)$ \\
Acremonium spp. & $1(1.9)$ \\
Scedosporium spp. & $1(1.9)$ \\
Mixed yeast and filamentous infection & $1(1.9)$ \\
Rhodotorula spp. + Alternaria spp. & $1(1.9)$ \\
Bacteria (co-infection with fungal keratitis) & \\
Total * & $32(27.4)$ \\
Gram-positive & $22(18.8)$ \\
Staphylococci spp. & $16(13.7)$ \\
Streptococcus pneumonia & $3(2.6)$ \\
Bacillus spp. & $2(1.7)$ \\
Enterococcus faecalis & $1(0.9)$ \\
Gram-negative & $10(8)$. \\
Moraxella spp. & $3(2.6)$ \\
Serratia marcescens & $3(2.6)$ \\
Pseudomonas spp. & $2(1.7)$ \\
Haemophilus influenza & $1(0.9)$ \\
Acinetobacter lwoffii & $1(0.9)$ \\
\hline Percentagecaculated based all &
\end{tabular}

* Percentage calculated based on all the included cases of fungal keratitis $(n=117)$.

Table 3. Summary of demographic factors and risk factors based on types of fungal keratitis (FK).

\begin{tabular}{|c|c|c|c|}
\hline \multirow{3}{*}{ Parameters } & Yeast FK & Filamentous FK & \multirow{3}{*}{$p$-Value } \\
\hline & Total $\mathrm{N}=33$ & Total $\mathbf{N}=18$ & \\
\hline & $\mathbf{N}(\%)$ & $\mathbf{N}(\%)$ & \\
\hline Age & $60.2 \pm 18.9$ & $51.3 \pm 22.9$ & 0.14 \\
\hline Gender & & & 0.34 \\
\hline Female & $21(63.6)$ & $9(50.0)$ & \\
\hline Male & $12(36.4)$ & $9(50.0)$ & \\
\hline Hospital & & & 0.57 \\
\hline QVH & $21(63.6)$ & $10(55.6)$ & \\
\hline$\widehat{\mathrm{QMC}}$ & $12(36.4)$ & $8(44.4)$ & \\
\hline Risk factors $\$$ & & & 0.31 \\
\hline OSD & $14(42.4)$ & $11(61.1)$ & 0.2 \\
\hline Prior corneal surgery & $7(21.2)$ & $2(11.1)$ & 0.37 \\
\hline Immunosuppression & $8(24.2)$ & 7 (38.9) & 0.27 \\
\hline Contact lens wear & $6(18.2)$ & $9(50.0)$ & $\underline{0.017}$ \\
\hline Topical corticosteroids & $6(18.2)$ & $1(5.6)$ & 0.21 \\
\hline Trauma & $2(6.1)$ & $1(5.6)$ & 0.94 \\
\hline
\end{tabular}

A case of poly-fungal keratitis, caused by both yeast and filamentous fungi, was excluded from the analysis. OSD = Ocular surface disease (including lid diseases due to small number). " Comparison between yeast-like and filamentous FK cases. Chi-square and unpaired $T$-test were used for categorical and continuous variables, respectively. The significant value is underlined. ${ }^{\$}$ Some patients had more than 1 risk factor identified.

All (100\%) patients were found to have at least one risk factor, with ocular surface disease $(60,51.3 \%)$, prior corneal surgery $(44,37.6 \%)$ and systemic immunosuppression $(42,35.9 \%)$ as the most common risk factors (Table 1). Ocular surface disease was the most common risk factor for both yeast and filamentous FK (Table 3). Contact lens wear was 
more commonly associated with filamentous FK than yeast FK (50.0\% vs. 18.2\%; $p=0.017)$ whereas prior corneal surgery and use of topical corticosteroids were more commonly observed in yeast FK than filamentous FK, though statistical significance was not achieved (both $p>0.05$ ).

\subsection{Clinical Characteristics}

The baseline clinical characteristics are summarised in Table 1. The mean interval between the onset of symptoms and the first presentation to the ophthalmic team was $9.5 \pm 14.9$ days. At baseline, 83 (70.9\%) patients presented with a CDVA of $<1.0$ logMAR. The most frequently observed clinical characteristics of the ulcer were moderate epithelial defect size $(45,38.5 \%)$, moderate infiltrate size $(47,40.2 \%)$, central location $(64,59.8 \%)$ and absence of hypopyon (77,65.8\%). Hospitalisation for intensive treatment was required in $95(81.2 \%)$ patients, with a mean hospitalisation duration of $18.9 \pm 16.3$ days. Except for presenting CDVA $(p=0.038)$, there was no significant difference in the demographic factors, risk factors and baseline clinical characteristics between culture-positive and culture-negative FK cases (all $p>0.05$; Table 1). Typical clinical features of FK were present in $93(79.5 \%)$ cases, with feathery border $(52,44.4 \%)$, satellite lesions $(39,33.3 \%)$ and deep stromal/endothelial plaque $(39,33.3 \%)$ being the most common features (Table 4 ). No significant difference in the typical features was noted between culture-positive and culture-negative cases.

Table 4. Typical clinical signs of culture-positive and culture-negative fungal keratitis.

\begin{tabular}{lccc}
\hline \multirow{2}{*}{ Clinical Features } & All Cases & Culture-Positive & Culture-Negative \\
\cline { 2 - 3 } & Total N = 117; & Total N = 52; & Total N= 65; \\
\cline { 2 - 4 } & $\mathbf{N ~ ( \% )}$ & $\mathbf{N}$ (\%) & N (\%) \\
\hline Typical clinical signs & & & 0.8 \\
Feathery border & $52(44.4)$ & $25(48.1)$ & $27(41.5)$ \\
Satellite lesions & $39(33.3)$ & $16(30.8)$ & $23(35.4)$ \\
Deep stromal/endothelial plaque & $39(33.3)$ & $14(26.9)$ & $25(38.5)$ \\
Multifocal lesion & $32(27.4)$ & $15(28.8)$ & $17(26.2)$ \\
Ring infiltrate & $29(24.8)$ & $13(25.0)$ & $16(24.6)$ \\
Number of typical clinical signs & & & $12(18.5)$ \\
None & $24(20.5)$ & $12(23.1)$ & $16(24.6)$ \\
1 & $31(26.5)$ & $15(28.8)$ & $22(33.8)$ \\
2 & $35(29.9)$ & $13(25.0)$ & $15(23.1)$ \\
\hline or more & $27(23.1)$ & $12(23.1)$ & 0.74 \\
\hline
\end{tabular}

\subsection{Medical and Surgical Treatment}

A total of 51 (43.6\%) patients were successfully treated with medical treatment alone, with $66(56.4 \%)$ patients requiring additional surgical interventions for controlling the infection and/or its sequelae. The most common choice of topical antifungal treatment was natamycin $(63,53.8 \%)$, voriconazole/other azole drops $(57,48.7 \%)$ and amphotericin $(51,43.6 \%)$. Adjuvant oral antifungal treatment and intrastromal voriconazole injections were administered in 19 (16.2\%) patients and 2 (1.7\%) patients, respectively. Emergency therapeutic/tectonic keratoplasty $(29,24.8 \%)$ was the most commonly performed surgery, followed by amniotic membrane transplant $(18,15.4 \%)$, corneal gluing $(17,14.5 \%)$, temporary/permanent tarsorrhaphy $(17,14.5 \%)$, evisceration $(9,7.7 \%)$, enucleation $(2,1.7 \%)$, therapeutic corneal cross-linking $(1,0.9 \%)$ and conjunctival hooding $(1,0.9 \%)$. Of the 29 tectonic/therapeutic keratopathy, 13 (44.8\%) of them failed at the final follow-up (mean duration $=24.3 \pm 22.7$ months). In addition, $10(8.5 \%)$ patients required elective optical penetrating keratoplasty after the resolution of infection. 


\subsection{Clinical Outcomes and Prognostic Factors}

The mean CDVA (in logMAR) was similar between initial presentation and final follow-up $(1.73 \pm 0.90$ vs. $1.67 \pm 1.08 ; p=0.36)$. From the initial presentation to final follow-up, the proportion of patients with CDVA of $\geq 1.0 \log$ MAR improved from $29.1 \%$ to $36.8 \%$, though not statistically significant $(p=0.21$; Figure 2$)$. Twenty-nine $(24.8 \%)$ patients had a final CDVA of PL or worse, including $11(9.4 \%)$ patients that eventually required evisceration or enucleation. Nine $(7.7 \%)$ patients were noted to have a significant cataract but the lens status did not have any significant influence on the visual outcome (therefore it was excluded from the final regression model). Multivariable logistic regression demonstrated that poor visual outcome (CDVA $<1.0 \log \mathrm{MAR})$ was significantly influenced by age $>50$ years old (OR 4.72; 95\% CI, 1.40-15.89; $p=0.012$ ), presenting CDVA of $<1.0$ logMAR (OR 14.92; 95\% CI, 4.19-53.18; $p<0.001)$ and infiltrate size $>3 \mathrm{~mm}(\mathrm{OR} 3.61 ; 95 \% \mathrm{CI}$, $1.11-11.81 ; p=0.034 ;$ Table 5).

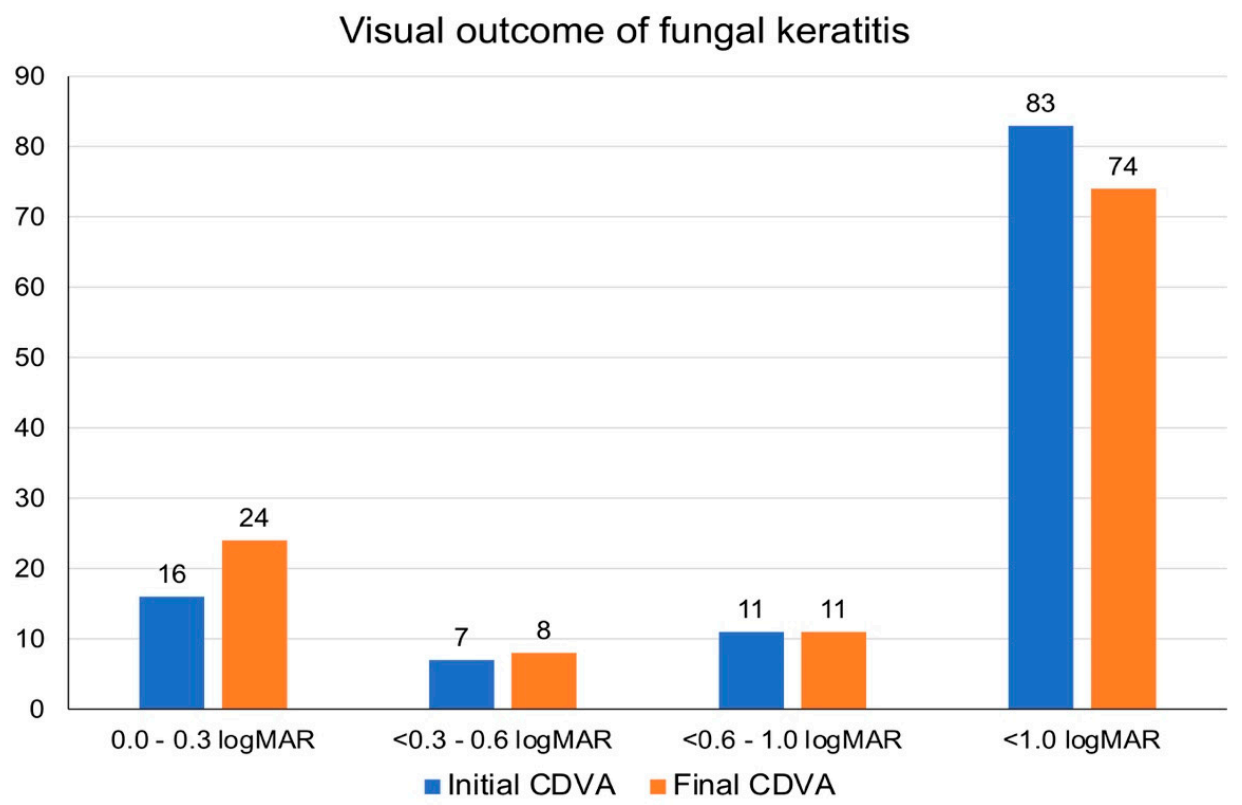

Figure 2. Comparison of corrected-distance-visual-acuity (CDVA) at initial presentation and final follow-up.

Table 5. Prognostic factors for poor visual outcome [defined as corrected-distance-visual-acuity (CDVA) of $<1.0$ logMAR]. and poor corneal healing (defined as $>60$ days to achieve complete healing or required tectonic/therapeutic keratoplasty, evisceration or enucleation) in fungal keratitis in the UK.

\begin{tabular}{|c|c|c|c|c|}
\hline \multirow[b]{2}{*}{ Parameters } & \multicolumn{2}{|c|}{ Poor Visual Outcome } & \multicolumn{2}{|c|}{ Poor Corneal Healing } \\
\hline & Odd Ratio $(95 \%$ CI) & $p$-Value * & Odd Ratio (95\% CI) & $p$-Value * \\
\hline Age $>50$ years & $4.72(1.40-15.89)$ & $\underline{0.012}$ & $5.81(1.83-18.37)$ & $\underline{0.003}$ \\
\hline Male gender & $0.99(0.33-3.00)$ & 0.99 & $0.93(0.33-2.72)$ & $\overline{0.91}$ \\
\hline Right eye & $1.13(0.37-3.43)$ & 0.83 & $2.86(0.95-8.61)$ & 0.06 \\
\hline Presenting CDVA $<1.0$ & $14.92(4.19-53.18)$ & $\leq 0.001$ & $3.91(1.19-12.82)$ & $\underline{0.025}$ \\
\hline Infiltrate size $>3 \mathrm{~mm}$ & $3.61(1.11-11.81)$ & $\overline{0.034}$ & $3.91(1.18-12.88)$ & $\overline{0.025}$ \\
\hline Central ulcer & $1.51(0.50-4.53)$ & $\overline{0.47}$ & $1.58(0.55-4.58)$ & $\overline{0.4}$ \\
\hline Presence of hypopyon & $2.87(0.81-10.18)$ & 0.1 & $2.78(0.78-9.86)$ & 0.12 \\
\hline Culture results & & 0.88 & & 0.44 \\
\hline Negative & Reference & - & Reference & - \\
\hline Yeast & $1.36(0.37-4.97)$ & 0.64 & $1.67(0.49-5.76)$ & 0.42 \\
\hline Filamentous & $0.95(0.19-4.71)$ & 0.95 & $2.74(0.52-14.41)$ & 0.23 \\
\hline Co-infection with bacteria & $1.70(0.49-5.93)$ & 0.4 & $0.71(0.23-2.26)$ & 0.57 \\
\hline
\end{tabular}

${ }^{*}$ Multivariable logistic regression analysis was performed. Significant $p$-values are underlined. 
A total of $97(82.9 \%)$ patients achieved complete corneal healing at final follow-up, with $11(9.4 \%)$ patients requiring evisceration/enucleation. Seven $(6.0 \%)$ patients were still undergoing active antifungal treatment at the final follow-up. The mean healing time was $2.71 \pm 2.86$ months, with $83(70.9 \%)$ patients having a corneal healing time of $>60$ days. Multivariable logistic regression analysis demonstrated that poor corneal healing was significantly affected by age $>50$ years (OR $5.81 ; 95 \% \mathrm{CI}, 1.83-18.37 ; p=0.003)$, presenting CDVA of $<1.0 \log$ MAR (OR 3.91; 95\% CI, 1.19-12.82; $p=0.025$ ) and infiltrate size $>3 \mathrm{~mm}$ (OR 3.91; 95\% CI, 1.18-12.88; $p=0.025$; Table 5). Other factors such as gender, ulcer location, presence of hypopyon, culture results, lens status and co-infection with bacteria did not significantly influence the visual outcome or the corneal healing time (all $p>0.05$ ).

\subsection{Complications}

There were various complications noted in this study, including threatened/actual corneal perforation $(38,32.5 \%)$, complete loss of vision/NLP $(18,15.4 \%)$, new onset of raised intraocular pressure $(>21 \mathrm{mmHg}) /$ glaucoma $(14,12.0 \%)$, recurrence of infection $(12$, $10.3 \%)$, endophthalmitis $(6,5.1 \%)$ and loss of eye $(11,9.4 \%)$.

\section{Discussion}

FK is a challenging clinical entity that often results in significant visual impairment and/or blindness. The annual incidence of FK has been estimated to be $>1$ million worldwide, highlighting the global impact of this disease [10]. Within the UK, several large epidemiological studies have reported a prevalence of 3.0-7.1\% of FK among all IK cases [3,27-29]. However, there is a lack of literature related to clinical studies on FK in the UK despite its clinical significance and impact. To the best of our knowledge, our study represents the first multi-centre study in the UK that had specifically examined the risk factors, causes and clinical outcomes of FK.

Studies have shown that the causative organisms of FK are influenced by the climates $[1,4,10,17,21,30]$. Yeast or yeast-like fungi such as Candida spp. are more commonly observed in temperate regions whereas filamentous fungi, particularly Fusarium spp. and Aspergillus spp., normally thrive in tropical climates $[1,17]$. In this study, we observed that Candida spp. accounted for the majority (62.3\%) of the culture-positive FK, followed by Fusarium spp. (17.0\%). This was similar to a previous London study where Candida spp. was responsible for $60 \%$ of all FK cases, [31]. though a recent London study [24]. observed Fusarium spp. (40.5\%) as the most common organism of FK, closely followed by Candida spp. (38.0\%). Khoo et al. [32]. similarly reported Candida spp. as the most common $(29.2 \%)$ fungal isolate for FK in Sydney, which falls in the temperate region. In contrast, the Asian Cornea Society Infectious Keratitis Study (ACSIKS), a large multi-centre study consisting of 8 countries and $>6000$ patients with infectious keratitis, demonstrated that filamentous fungi such as Fusarium spp. (18.3\%) and Aspergillus spp. (8.3\%) were two of the top three organisms of all IK in this region, particularly India and China [4]. Similarly, the Queensland Microbial Keratitis Database demonstrated filamentous fungi as the most common group of fungal pathogens $(76.9 \%)$ in Queensland, which is mainly a tropical and subtropical region [2].

Risk factors of FK have also been shown to vary considerably among different geographical regions. More importantly, the underlying risk factors have an important contributory role to the causative fungal pathogen. Corneal trauma with the vegetative matter was consistently reported as the most common risk factor of FK in developing countries, particularly those with high agricultural activity $[4,17,33,34]$. These FK cases were frequently caused by filamentous fungi, namely Fusarium spp. and Aspergillus spp. [17,33]. This could help explain the low prevalence of filamentous FK in our study where trauma only accounted for $6.0 \%$ of all FK cases. In addition, contact lens wear has been shown to be more commonly implicated in filamentous FK than yeast FK, which was demonstrated by our study and other studies $[24,30]$. On the other hand, yeast infections, particularly Candida spp., were commonly observed in eyes with ocular surface diseases, previous 
history of corneal transplantation and use of topical corticosteroids [24,30,35]. We similarly observed that yeast was more commonly associated with prior corneal surgery and the use of topical corticosteroids, though not statistically significant, likely due to a type II error as a result of low sample size. With the shifting trend in penetrating keratoplasty to lamellar keratoplasty, interface infectious keratitis, including Candida-related infection following endothelial keratoplasty, has become increasingly common in the clinic and poses significant diagnostic and therapeutic challenges [35-37]. Therefore, knowledge of the risk factors can provide useful clues to the underlying causative organisms, potentially guiding the choice of antifungal treatment, especially in culture-negative FK cases.

Ocular surface disease (51.3\%) and prior corneal surgeries (37.6\%) were shown to be the main risk factor of FK in this study. These findings could be attributed to the nature and scope of ophthalmic work provided by the two included study centres, namely the Queen's Medical Centre, Nottingham and the Queen Victoria Hospital, East Grinstead. Both centres were tertiary ophthalmic referral centres in the UK where complex ocular surface cases such as cicatricial conjunctival diseases, graft-versus-host-disease, limbal stem cell deficiency and neurotrophic keratopathy, amongst others, were being managed, in addition to common conditions such as dry eye disease and infectious keratitis. In addition, there was also a relatively low prevalence of trauma and fewer agricultural activities in the UK, compared to other countries like India and China where trauma is a common risk factor $[4,17,33,34]$.

In this study, $63 \%$ of the patients had a final vision of $<1.0 \log$ MAR (mean vision $=$ $1.67 \pm 1.08)$. In addition, $25 \%$ of the patients required emergency tectonic/therapeutic keratoplasty, highlighting the significant impact of this disease. The poor outcome was similarly observed by Khoo et al. [32]. who reported a median final vision of $1.5 \log$ MAR in patients with FK. In addition, various studies have reported that $25-50 \%$ of the patients with FK required additional surgical interventions to resolve the infection, most commonly in the form of therapeutic/tectonic keratoplasty $[15,30]$. Therapeutic corneal cross-linking $(\mathrm{CXL})$ has also recently emerged as an attractive adjuvant therapy for treating infectious keratitis [38]. although the benefit for FK remained elusive [39,40]. In this study, therapeutic CXL was performed in one patient, which successfully controlled the infection and prevented corneal perforation and the need for emergency keratoplasty. However, it is also important to note that infectious keratitis may also occur following CXL, which has been shown in our study (one patient) and other studies [41,42].

Prajna et al. [43]. previously demonstrated that the visual outcome (at 3 months) was significantly affected by older age, worse presenting visual acuity and larger presenting infiltrate size. In addition, time to complete cornea re-epithelialisation was proportionately correlated with the infiltrate size and increased age whereas larger epithelial defect significantly increased the risk of corneal perforation. Another study by the same group similarly observed the risk of corneal perforation in FK was significantly influenced by the increased size of infiltrate as well as the presence of hypopyon and involvement of $1 / 3$ posterior cornea at presentation [15]. This was similarly observed in our study where increased age and large infiltrate size $(>3 \mathrm{~mm}$ ) served as significant negative predictive factors for visual outcome and corneal healing.

Compared to our recent bacterial keratitis study, [25]. FK was shown to be associated with poorer visual outcomes, a higher need for hospitalisation (with longer duration), longer healing time and higher rate of complications. This was similarly observed in many other studies where FK was shown to fare worse than bacterial keratitis, [4,32,44]. highlighting the significant impact of FK on the patients, healthcare systems and economy (due to loss of work productivity).

Our study represents one of the largest studies in the UK specifically examining the epidemiology, risk factors, causes and outcomes of FK. In addition, we examined the prognostic factors of various clinically important outcomes of FK, including the visual outcome and time to complete corneal healing. The main limitation of this study was the inclusion of culture-negative presumed FK cases. However, we had examined the medical case notes to 
ensure that all the included cases were true FK cases based on the clinical presentation and clinical course. This was further supported by the similar baseline characteristics of culturepositive and culture-negative FK cases in our study. The issue with low culture yield in infectious keratitis has been a recurrent clinical theme $[1,25,45]$. In the future, it is envisaged that novel technologies, including polymerase chain reaction (PCR), [46,47], IVCM [48], next-generation sequencing, [49-51], matrix-assisted laser/desorption ionisation-time of flight-mass spectrometry (MALDI-TOF-MS) [14,52] and artificial intelligence-assisted platforms [53-56] would be able to enhance the diagnostic yield and accuracy of infectious keratitis. As contact lenses serve as an important risk factor for FK, future studies examining the influence of the types and brands of CL on the microbiological profiles and risk of infection would be valuable. Comprehensive analysis of antifungal susceptibility of fungal isolates of FK will also be performed in the future to examine the correlation between the susceptibility results and the clinical outcomes.

In conclusion, FK represents an uncommon but challenging ocular pathology that often results in a poor visual outcome, with a high need for surgical interventions. Current therapeutic options are limited in clinical practice. Novel therapies such as host defence peptides (also known as antimicrobial peptides) and phage therapy have demonstrated promise as a potential treatment for treating infectious keratitis and future investigations of these therapy for FK would be valuable [57-61].

Author Contributions: Conceptualization, D.S.J.T.; methodology, D.S.J.T.; data collection: D.S.J.T., M.G. and B.K.; data analysis, D.S.J.T.; data interpretation, D.S.J.T., M.S.E., D.L., S.H., D.G.S. and H.S.D.; writing—original draft preparation, D.S.J.T.; writing—review and editing, M.G., B.K., M.S.E., D.L., S.H., D.G.S. and H.S.D.; visualization, D.S.J.T.; supervision, D.S.J.T.; project administration, D.S.J.T., M.S.E., D.G.S. and H.S.D.; funding acquisition, D.S.J.T. All authors have read and agreed to the published version of the manuscript.

Funding: D.S.J.T. acknowledges support from the Medical Research Council/Fight for Sight Clinical Research Fellowship (MR/T001674/1) and the Fight for Sight/John Lee, Royal College of Ophthalmologists Primer Fellowship (24CO4).

Institutional Review Board Statement: The study was conducted according to the guidelines of the Declaration of Helsinki and approved as a clinical audit by the Clinical Governance team in both Nottingham University Hospitals NHS Trust (Ref: 19-265C) and Queen Victoria Hospital NHS Foundation Trust (Ref: 21-539).

Informed Consent Statement: Patient consent was waived as this was a clinical audit that involved only retrospective analysis of the medical case notes.

Data Availability Statement: All relevant data are provided in this study.

Conflicts of Interest: The authors declare no conflict of interest.

\section{References}

1. Ting, D.S.J.; Ho, C.S.; Deshmukh, R.; Said, D.G.; Dua, H.S. Infectious keratitis: An update on epidemiology, causative microorganisms, risk factors, and antimicrobial resistance. Eye 2021, 35, 1084-1101. [CrossRef] [PubMed]

2. Green, M.; Carnt, N.; Apel, A.; Stapleton, F. Queensland Microbial Keratitis Database: 2005-2015. Br. J. Ophthalmol. 2019, 103, 1481-1486. [CrossRef]

3. Ting, D.S.J.; Ho, C.S.; Cairns, J.; Elsahn, A.; Al-Aqaba, M.; Boswell, T.; Said, D.G.; Dua, H.S. 12-year analysis of incidence, microbiological profiles and in vitro antimicrobial susceptibility of infectious keratitis: The Nottingham Infectious Keratitis Study. Br. J. Ophthalmol. 2021, 105, 328-333. [CrossRef] [PubMed]

4. Khor, W.-B.; Prajna, V.N.; Garg, P.; Mehta, J.S.; Xie, L.; Liu, Z.; Padilla, M.D.B.; Joo, C.-K.; Inoue, Y.; Goseyarakwong, P.; et al. The Asia Cornea Society Infectious Keratitis Study: A Prospective Multicenter Study of Infectious Keratitis in Asia. Am. J. Ophthalmol. 2018, 195, 161-170. [CrossRef]

5. Ting, D.S.J.; Ho, C.S.; Cairns, J.; Gopal, B.P.; Elsahn, A.; Al-Aqaba, M.; Boswell, T.; Said, D.G.; Dua, H.S. Seasonal patterns of incidence, demographic factors and microbiological profiles of infectious keratitis: The Nottingham Infectious Keratitis Study. Eye 2021, 35, 2543-2549. [CrossRef]

6. Lin, L.; Duan, F.; Yang, Y.; Lou, B.; Liang, L.; Lin, X. Nine-year analysis of isolated pathogens and antibiotic susceptibilities of microbial keratitis from a large referral eye center in southern China. Infect. Drug Resist. 2019, 12, 1295-1302. [CrossRef] [PubMed] 
7. Arshad, S.; Petsoglou, C.; Lee, T.; Al-Tamimi, A.; Carnt, N.A. Twenty years since the Herpetic Eye Disease Study: Lessons, developments and applications to clinical practice. Clin. Exp. Optom. 2021, 104, 396-405. [CrossRef]

8. Ting, D.S.J.; Ghosh, N.; Ghosh, S. Herpes zoster ophthalmicus. BMJ 2019, 364, k5234. [CrossRef] [PubMed]

9. Carnt, N.; Robaei, D.; Minassian, D.C.; Dart, J.K.G. Acanthamoeba keratitis in 194 patients: Risk factors for bad outcomes and severe inflammatory complications. Br. J. Ophthalmol. 2018, 102, 1431-1435. [CrossRef]

10. Brown, L.; Leck, A.K.; Gichangi, M.; Burton, M.J.; Denning, D.W. The global incidence and diagnosis of fungal keratitis. Lancet Infect. Dis. 2021, 21, e49-e57. [CrossRef]

11. Lin, C.C.; Lalitha, P.; Srinivasan, M.; Prajna, N.V.; McLeod, S.D.; Acharya, N.R.; Lietman, T.M.; Porco, T.C. Seasonal Trends of Microbial Keratitis in South India. Cornea 2012, 31, 1123-1127. [CrossRef]

12. Cunha, A.M.; Loja, J.T.; Torrão, L.; Moreira, R.; Pinheiro, D.; Falcão-Reis, F.; Pinheiro-Costa, J. A 10-Year Retrospective Clinical Analysis of Fungal Keratitis in a Portuguese Tertiary Centre. Clin. Ophthalmol. 2020, 14, 3833-3839. [CrossRef]

13. Ting, D.S.J.; Bignardi, G.; Koerner, R.; Irion, L.D.; Johnson, E.; Morgan, S.J.; Ghosh, S. Polymicrobial Keratitis with Cryptococcus curvatus, Candida parapsilosis, and Stenotrophomonas maltophilia after Penetrating Keratoplasty: A Rare Case Report with Literature Review. Eye Contact Lens Sci. Clin. Pract. 2019, 45, e5-e10. [CrossRef]

14. Ting, D.S.J.; Mckenna, M.; Sadiq, S.N.; Martin, J.; Mudhar, H.S.; Meeney, A.; Patel, T. Arthrographis kalrae Keratitis Complicated by Endophthalmitis: A Case Report with Literature Review. Eye Contact Lens Sci. Clin. Pract. 2020, 46, e59-e65. [CrossRef] [PubMed]

15. Prajna, N.V.; Krishnan, T.; Rajaraman, R.; Patel, S.; Shah, R.; Srinivasan, M.; Das, M.; Ray, K.J.; Oldenburg, C.E.; McLeod, S.D.; et al. Predictors of Corneal Perforation or Need for Therapeutic Keratoplasty in Severe Fungal Keratitis: A Secondary Analysis of the Mycotic Ulcer Treatment Trial II. JAMA Ophthalmol. 2017, 135, 987-991. [CrossRef] [PubMed]

16. Said, D.G.; Rallis, K.I.; Al-Aqaba, M.A.; Ting, D.S.; Dua, H.S. Surgical management of infectious keratitis. Ocul. Surf. 2021, S1542. [CrossRef]

17. Lalitha, P.; Prajna, N.V.; Manoharan, G.; Srinivasan, M.; Mascarenhas, J.; Das, M.; D’Silva, S.S.; Porco, T.C.; Keenan, J.D. Trends in bacterial and fungal keratitis in South India, 2002-2012. Br. J. Ophthalmol. 2015, 99, 192-194. [CrossRef]

18. Lalitha, P.; Prajna, N.V.; Oldenburg, C.E.; Srinivasan, M.; Krishnan, T.; Mascarenhas, J.; Vaitilingam, C.M.; McLeod, S.D.; Zegans, M.E.; Porco, T.C.; et al. Organism, Minimum Inhibitory Concentration, and Outcome in a Fungal Corneal Ulcer Clinical Trial. Cornea 2012, 31, 662-667. [CrossRef] [PubMed]

19. Dan, J.; Zhou, Q.; Zhai, H.; Cheng, J.; Wan, L.; Ge, C.; Xie, L. Clinical analysis of fungal keratitis in patients with and without diabetes. PLOS ONE 2018, 13, e0196741. [CrossRef]

20. Fernandes, M.; Vira, D.; Dey, M.; Tanzin, T.; Kumar, N.; Sharma, S. Comparison between Polymicrobial and Fungal Keratitis: Clinical Features, Risk Factors, and Outcome. Am. J. Ophthalmol. 2015, 160, 873-881.e2. [CrossRef] [PubMed]

21. Ganguly, S.; Salma, K.C.; Sharma, M.; Bastola, P.; Pradhan, R.; Kansakar, I. Pattern of fungal isolates in cases of corneal ulcer in the western periphery of Nepal. Nepal. J. Ophthalmol. 2011, 3, 118-122. [CrossRef]

22. Khurana, A.; Chanda, S.; Bhagat, P.; Aggarwal, S.; Sharma, M.; Chauhan, L. Clinical characteristics, predisposing factors, and treatment outcome of Curvularia keratitis. Indian J. Ophthalmol. 2020, 68, 2088-2093. [CrossRef] [PubMed]

23. Mascarenhas, J.; Lalitha, P.; Prajna, N.V.; Srinivasan, M.; Das, M.; D’Silva, S.S.; Oldenburg, C.E.; Borkar, D.S.; Esterberg, E.J.; Lietman, T.M.; et al. Acanthamoeba, Fungal, and Bacterial Keratitis: A Comparison of Risk Factors and Clinical Features. Am. J. Ophthalmol. 2014, 157, 56-62. [CrossRef]

24. Ong, H.S.; Fung, S.S.; Macleod, D.; Dart, J.K.; Tuft, S.J.; Burton, M.J. Altered Patterns of Fungal Keratitis at a London Ophthalmic Referral Hospital: An Eight-Year Retrospective Observational Study. Am. J. Ophthalmol. 2016, 168, 227-236. [CrossRef] [PubMed]

25. Ting, D.S.J.; Cairns, J.; Gopal, B.P.; Ho, C.S.; Krstic, L.; Elsahn, A.; Lister, M.; Said, D.G.; Dua, H.S. Risk Factors, Clinical Outcomes, and Prognostic Factors of Bacterial Keratitis: The Nottingham Infectious Keratitis Study. Front. Med. 2021, 8, 715118. [CrossRef] [PubMed]

26. Lange, C.; Feltgen, N.; Junker, B.; Schulze-Bonsel, K.; Bach, M. Resolving the clinical acuity categories "hand motion" and "counting fingers" using the Freiburg Visual Acuity Test (FrACT). Graefe's Arch. Clin. Exp. Ophthalmol. 2009, 247, 137-142. [CrossRef] [PubMed]

27. Tan, S.Z.; Walkden, A.; Au, L.; Fullwood, C.; Hamilton, A.; Qamruddin, A.; Armstrong, M.; Brahma, A.K.; Carley, F. Twelve-year analysis of microbial keratitis trends at a UK tertiary hospital. Eye 2017, 31, 1229-1236. [CrossRef]

28. Ting, D.S.J.; Settle, C.; Morgan, S.J.; Baylis, O.; Ghosh, S. A 10-year analysis of microbiological profiles of microbial keratitis: The North East England Study. Eye 2018, 32, 1416-1417. [CrossRef]

29. Tavassoli, S.; Nayar, G.; Darcy, K.; Grzeda, M.; Luck, J.; Williams, O.M.; Tole, D. An 11-year analysis of microbial keratitis in the South West of England using brain-heart infusion broth. Eye 2019, 33, 1619-1625. [CrossRef]

30. Keay, L.; Gower, E.W.; Iovieno, A.; Oechsler, R.A.; Alfonso, E.C.; Matoba, A.; Colby, K.; Tuli, S.S.; Hammersmith, K.; Cavanagh, D.; et al. Clinical and Microbiological Characteristics of Fungal Keratitis in the United States, 2001-2007: A Multicenter Study. Ophthalmology 2011, 118, 920-926. [CrossRef] [PubMed]

31. Galarreta, D.J.; Tuft, S.J.; Ramsay, A.; Dart, J.K. Fungal keratitis in London: Microbiological and clinical evaluation. Cornea 2007, 26, 1082-1086. [CrossRef]

32. Khoo, P.; Cabrera-Aguas, M.; Nguyen, V.; Lahra, M.M.; Watson, S.L. Microbial keratitis in Sydney, Australia: Risk factors, patient outcomes, and seasonal variation. Graefe's Arch. Clin. Exp. Ophthalmol. 2020, 258, 1745-1755. [CrossRef] 
33. Wang, L.; Wang, L.; Han, L.; Yin, W. Study of Pathogens of Fungal Keratitis and the Sensitivity of Pathogenic Fungi to Therapeutic Agents with the Disk Diffusion Method. Curr. Eye Res. 2015, 40, 1095-1101. [CrossRef] [PubMed]

34. Manikandan, P.; Abdel-Hadi, A.; Randhir Babu Singh, Y.; Revathi, R.; Anita, R.; Banawas, S.; Bin Dukhyil, A.A.; Alshehri, B.; Shobana, C.S.; Panneer Selvam, K.; et al. Fungal Keratitis: Epidemiology, Rapid Detection, and Antifungal Susceptibilities of Fusarium and Aspergillus Isolates from Corneal Scrapings. Biomed. Res. Int. 2019, 2019, 6395840. [CrossRef]

35. Song, A.; Deshmukh, R.; Lin, H.; Ang, M.; Mehta, J.S.; Chodosh, J.; Said, D.G.; Dua, H.S.; Ting, D.S. Post-keratoplasty Infectious Keratitis: Epidemiology, Risk Factors, Management, and Outcomes. Front. Med. 2021, 8, 707242. [CrossRef]

36. Ting, D.S.J.; Said, D.G.; Dua, H.S. Interface Haze after Descemet Stripping Automated Endothelial Keratoplasty. JAMA Ophthalmol. 2019, 137, 1201. [CrossRef]

37. Sharma, N.; Kaur, M.; Titiyal, J.S.; Aldave, A. Infectious keratitis after lamellar keratoplasty. Surv. Ophthalmol. 2021, 66, 623-643. [CrossRef] [PubMed]

38. Ting, D.S.J.; Henein, C.; Said, D.G.; Dua, H.S. Photoactivated chromophore for infectious keratitis-Corneal cross-linking (PACK-CXL): A systematic review and meta-analysis. Ocul. Surf. 2019, 17, 624-634. [CrossRef] [PubMed]

39. Prajna, N.V.; Radhakrishnan, N.; Lalitha, P.; Austin, A.; Ray, K.J.; Keenan, J.D.; Porco, T.C.; Lietman, T.M.; Rose-Nussbaumer, J. Cross-Linking-Assisted Infection Reduction: A Randomized Clinical Trial Evaluating the Effect of Adjuvant Cross-Linking on Outcomes in Fungal Keratitis. Ophthalmology 2020, 127, 159-166. [CrossRef]

40. Ting, D.S.J.; Henein, C.; Said, D.G.; Dua, H.S. Re: Prajna et al. Cross-Linking-Assisted Infection Reduction (CLAIR): A randomized clinical trial evaluating the effect of adjuvant cross-linking on outcomes in fungal keratitis. Ophthalmology 2020, 127, e55-e56. [CrossRef]

41. Khoo, P.; Cabrera-Aguas, M.; Watson, S.L. Microbial Keratitis after Corneal Collagen Cross-Linking for Corneal Ectasia. Asia-Pac. J. Ophthalmol. 2021, 10, 355-359. [CrossRef]

42. Ting, D.S.J.; Bandyopadhyay, J.; Patel, T. Microbial keratitis complicated by acute hydrops following corneal collagen cross-linking for keratoconus. Clin. Exp. Optom. 2019, 102, 434-436. [CrossRef]

43. Prajna, N.V.; Krishnan, T.; Mascarenhas, J.; Srinivasan, M.; Oldenburg, C.E.; Toutain-Kidd, C.M.; Sy, A.; McLeod, S.D.; Zegans, M.E.; Acharya, N.R.; et al. Predictors of outcome in fungal keratitis. Eye 2012, 26, 1226-1231. [CrossRef]

44. Prajna, N.V.; Srinivasan, M.; Lalitha, P.; Krishnan, T.; Rajaraman, R.; Ravindran, M.; Mascarenhas, J.; Oldenburg, C.E.; Ray, K.J.; McLeod, S.D.; et al. Differences in Clinical Outcomes in Keratitis Due to Fungus and Bacteria. JAMA Ophthalmol. 2013, 131, 1088-1089. [CrossRef]

45. Sharma, S.; Rathi, V.; Murthy, S.; Mitra, S.; Yamjala, B.; Mohamed, A. Masked comparison of trypan blue stain and potassium hydroxide with calcofluor white stain in the microscopic examination of corneal scrapings for the diagnosis of microbial keratitis. Indian J. Ophthalmol. 2021, 69, 2457. [CrossRef] [PubMed]

46. Somerville, T.F.; Corless, C.E.; Sueke, H.; Neal, T.; Kaye, S.B. 16S Ribosomal RNA PCR versus Conventional Diagnostic Culture in the Investigation of Suspected Bacterial Keratitis. Transl. Vis. Sci. Technol. 2020, 9, 2. [CrossRef] [PubMed]

47. Holmgaard, D.B.; Barnadas, C.; Mirbarati, S.H.; O’Brien, L.A.; Nielsen, H.V.; Stensvold, C.R. Detection and Identification of Acanthamoeba and Other Nonviral Causes of Infectious Keratitis in Corneal Scrapings by Real-Time PCR and Next-Generation Sequencing-Based 16S-18S Gene Analysis. J. Clin. Microbiol. 2021, 59, e02224-20. [CrossRef]

48. Chidambaram, J.D.; Prajna, N.V.; Palepu, S.; Lanjewar, S.; Shah, M.; Elakkiya, S.; Macleod, D.; Lalitha, P.; Burton, M. In Vivo Confocal Microscopy Cellular Features of Host and Organism in Bacterial, Fungal, and A. canthamoeba Keratitis. Am. J. Ophthalmol. 2018, 190, 24-33. [CrossRef] [PubMed]

49. Ung, L.; Bispo, P.J.; Doan, T.; Van Gelder, R.N.; Gilmore, M.S.; Lietman, T.; Margolis, T.P.; Zegans, M.E.; Lee, C.S.; Chodosh, J. Clinical metagenomics for infectious corneal ulcers: Rags to riches? Ocul. Surf. 2019, 18, 1-12. [CrossRef]

50. Lalitha, P.; Prajna, N.V.; Sikha, M.; Gunasekaran, R.; Hinterwirth, A.; Worden, L.; Chen, C.; Zhong, L.; Liu, Z.; Lietman, T.M.; et al. Evaluation of Metagenomic Deep Sequencing as a Diagnostic Test for Infectious Keratitis. Ophthalmology 2021, 128, 473-475. [CrossRef] [PubMed]

51. Ting, D.S.J.; Gopal, B.P.; Deshmukh, R.; Seitzman, G.D.; Said, D.G.; Dua, H.S. Diagnostic armamentarium of infectious keratitis: A comprehensive review. Ocul. Surf. 2021, in press.

52. Watson, S.; Cabrera-Aguas, M.; Khoo, P.; Pratama, R.; Gatus, B.J.; Gulholm, T.; El-Nasser, J.; Lahra, M.M. Keratitis antimicrobial resistance surveillance program, Sydney, Australia: 2016 Annual Report. Clin. Exp. Ophthalmol. 2019, 47, 20-25. [CrossRef]

53. Ting, D.S.J.; Foo, V.H.; Yang, L.W.Y.; Sia, J.T.; Ang, M.; Lin, H.; Chodosh, J.; Mehta, J.S.; Ting, D.S.W. Artificial intelligence for anterior segment diseases: Emerging applications in ophthalmology. Br. J. Ophthalmol. 2021, 105, 158-168. [CrossRef] [PubMed]

54. Tiwari, M.; Piech, C.; Baitemirova, M.; Prajna, N.V.; Srinivasan, M.; Lalitha, P.; Villegas, N.; Balachandar, N.; Chua, J.T.; Redd, T.; et al. Differentiation of Active Corneal Infections from Healed Scars Using Deep Learning. Ophthalmology 2021, 0161. [CrossRef] [PubMed]

55. Hung, N.; Shih, A.; Lin, C.; Kuo, M.-T.; Hwang, Y.-S.; Wu, W.-C.; Kuo, C.-F.; Kang, E.; Hsiao, C.-H. Using Slit-Lamp Images for Deep Learning-Based Identification of Bacterial and Fungal Keratitis: Model Development and Validation with Different Convolutional Neural Networks. Diagnostics 2021, 11, 1246. [CrossRef]

56. Rampat, R.; Deshmukh, R.; Chen, X.; Ting, D.S.; Said, D.G.; Dua, H.S.; Ting, D.S. Artificial Intelligence in Cornea, Refractive Surgery, and Cataract. Asia-Pac. J. Ophthalmol. 2021, 10, 268-281. [CrossRef] 
57. Ting, D.S.J.; Beuerman, R.W.; Dua, H.S.; Lakshminarayanan, R.; Mohammed, I. Strategies in Translating the Therapeutic Potentials of Host Defense Peptides. Front. Immunol. 2020, 11, 983. [CrossRef]

58. Mayandi, V.; Xi, Q.; Goh, E.T.L.; Koh, S.K.; Toh, T.Y.J.; Barathi, V.A.; Fazil, M.H.U.T.; Chalasani, M.L.S.; Varadarajan, J.; Ting, D.S.J.; et al. Rational Substitution of $\varepsilon$-Lysine for $\alpha$-Lysine Enhances the Cell and Membrane Selectivity of Pore-Forming Melittin. J. Med. Chem. 2020, 63, 3522-3537. [CrossRef]

59. Mohammed, I.; Mohanty, D.; Said, D.G.; Barik, M.R.; Reddy, M.M.; Alsaadi, A.; Das, S.; Dua, H.S.; Mittal, R. Antimicrobial peptides in human corneal tissue of patients with fungal keratitis. Br. J. Ophthalmol. 2020, 105, 1172-1177. [CrossRef]

60. Ting, D.S.J.; Goh, E.T.L.; Mayandi, V.; Busoy, J.M.F.; Aung, T.T.; Periayah, M.H.; Nubile, M.; Mastropasqua, L.; Said, D.G.; Htoon, H.M.; et al. Hybrid derivative of cathelicidin and human beta defensin-2 against Gram-positive bacteria: A novel approach for the treatment of bacterial keratitis. Sci. Rep. 2021, 11, 1-14. [CrossRef]

61. Górski, A.; Bollyky, P.L.; Przybylski, M.; Borysowski, J.; Międzybrodzki, R.; Jończyk-Matysiak, E.; Weber-Dąbrowska, B. Perspectives of Phage Therapy in Non-bacterial Infections. Front. Microbiol. 2019, 9, 3306. [CrossRef] [PubMed] 